\title{
Os usos da diversidade cultural no mercado mundial de moda: a dinâmica das identidades nacionais na globalização
}

Miqueli Michetti*

Resumo: $\mathrm{O}$ trabalho analisa as relações entre o desenvolvimento da chamada "moda brasileira" e o processo de mundialização. O fenômeno aparentemente paradoxal é explicado a partir da conjuntura global de valorização da idéia de diversidade cultural, a qual passa a ser operada no mercado mundial de moda, onde as identidades são negociadas de maneira reflexiva, relacional e hierárquica. É nesse novo contexto que a identidade nacional é rearticulada e que a criação de uma "moda brasileira" adquire sentido histórico.

Palavras-chave: mundialização, diversidade cultural, identidades nacionais, moda brasileira.

\begin{abstract}
This paper aims to analyse the relationship between the development of the so-called "Brazilian fashion" and the processes of cultural and economic globalization. Even though the conjunction of these phenomena appears to be paradoxical at a first glance, it can be explained by the context of valorization of the idea or discourse of cultural diversity, which is currently operated in the world market of fashion. In this new context, identities are negotiated in a reflexive, relational and hierarchical way and the Brazilian national identity in particular is rearticulated as representing "diversity". It is within this new context that the contemporary creation of a "Brazilian fashion" acquires historical meaning.
\end{abstract}

Key-words: globalization, cultural diversity, national identities, Brazilian fashion

\footnotetext{
* Mestrado em Sociologia pela Universidade Estadual Paulista e, doutoranda em sociologia do Instituto de Filosofia e Ciências Humanas da Universidade Estadual de Campinas. E-mail: miquelimichetti@yahoo.com.br.
} 
Miqueli Miquetti

\section{Os usos da diversidade cultural no mercado mundial de moda: a dinâmica das identidades nacionais na globalização ${ }^{1}$}

Desde que veio ao mundo no Japão de 1939 até sua ida a Paris em 1964, Kenzo Takada era um jovem tão japonês quanto qualquer outro jovem nascido no Japão. Formado no renomado Bunka Fashion College, ele muda-se para Paris, onde, após trabalhar para outras empresas do setor de moda, abre uma butique para distribuir sua própria marca e lança sua primeira coleção em 1970. Em palestra proferida no Brasil2, ele comentou que antes de inaugurar a butique, ele costumava seguir o que estava em voga e que foi no momento da concepção de sua primeira coleção que ele se deu conta de sua "identidade nacional". É nessa ocasião que o estilista se questiona sobre qual seria sua "identidade em um país estrangeiro" e se pergunta como, enquanto japonês, poderia ser melhor que um designer francês. Eis que ele conclui que deveria "tirar proveito de ser japonês, usar motivos japoneses, o quimono..."3

Em uma conjuntura de grande transformação da indústria da moda, sua estratégia deu certo e dois anos depois do lançamento de sua marca, ela já era mundialmente reconhecida. Tanto que Gilda Chataignier (2010, p.153) nos conta que na mesma década de 1970, Kenzo teria sido "literalmente copiado" por uma loja instalada em Copacabana, que teria ousado manter mesmo o nome da fachada: Kenzo Jap. O fato teria ido à justiça e depois disso Kenzo teria proibido que brasileiros freqüentassem seus concorridos desfiles.

Pensamos possuir duas boas justificativas para curiosamente começar a análise da situação da "moda brasileira" no mercado mundial de moda atualmente ávido por manifestações do que seria "diversidade cultural" - com a história de um estilista japonês que constrói sua carreira em Paris. Primeiramente, o percurso de Kenzo nos informa sobre algumas importantes transformações pelas quais passou a moda nas últimas décadas. Depois, e mais importante, porque o mesmo Kenzo que teria vetado a participação brasileira em seus desfiles na década de 1970 se transforma, em 2010, no "representante da moda brasileira no Japão." Trata-se do mesmo Kenzo, mas em conjunturas distintas.

O estilista japonês esteve no Brasil em agosto de 2010 a convite da Associação brasileira de indústria têxtil e confecções (Abit), no quadro do Programa

\footnotetext{
${ }^{1}$ Agradeço à FAPESP e ao programa de estágio no exterior da CAPES pelas bolsas de estudos que permitiram a realização da pesquisa que fundamenta o presente texto.

${ }^{2}$ Palestra proferida no SENAC-SP em 21/06/08.

3 Sobre a história do quimono e suas "releituras" na moda contemporânea consultar Liza Crihfield Dalby. Kimono : Fashioning Culture.
} 
Os usos da diversidade cultural no mercado mundial de moda: a dinâmica das identidades nacionais na globalização

Estratégico da Cadeia Têxtil Brasileira (Texbrasil), desenvolvido pela Abit em parceria com a Agência brasileira de promoção de exportações e investimentos (ApexBrasil). Além de conferir palestra na sede da associação em São Paulo e de atender jornalistas e estudantes, o novo "representante da moda brasileira" teria aproveitado sua visita ao país para conhecer novos parceiros de negócios. Após afirmar estar honrado por poder "visitar o país pela segunda vez" - embora tenha afirmado em outra ocasião já ter estado por aqui 4 ou 5 vezes nas décadas de 1970 e 1980 para visitar o Rio e a Bahia, tendo esta sido inclusive tema de uma de suas coleções - ele assevera que "este é um país cheio de energia e que acredito que vai liderar o mundo da moda do século XXI. A parceria com o Texbrasil é a oportunidade de contribuir para a moda brasileira, francesa e japonesa". ${ }^{4}$

Essa mudança radical na apreciação da moda do Brasil por parte do japonês tem relação com o inegável desenvolvimento do setor no país nas últimas décadas, mas parece também ser vinculada à "virada" econômica e simbólica da moda em direção à positividade da idéia de diversidade a partir da década de 1970. Este movimento parece ter sido um condicionante do sucesso de Kenzo e dos outros estilistas japoneses que se instalaram em Paris entre 1970 e 1981, como Issey Miyake, Hanae Mori, Rei Kawakubo e Yohji Yamamoto (Ortiz, 2000, p.149; Laver 2002, p.277), e atualmente condicionaria a inserção da moda do Brasil no mercado mundial. É nessa conjuntura econômica e cultural mais ampla que a idéia de "moda brasileira" adquire sentido histórico inédito, visto que se relaciona a um contexto de mudanças na organização da moda historicamente consagrada. Assim, nosso caso de abertura, que poderia constar como mera "atualidade", permite estabelecer um fio de compreensão da importância de Kenzo na moda "mundial" a partir dos anos 1970 e, principalmente, do afeto que a moda do Brasil, outrora denunciada por cópia ilegal, passa a despertar no Kenzo do ano 2010.

Antes de passarmos às transformações gerais no funcionamento do mercado mundial de moda gostaríamos de fazer uma ressalva terminológica.

No presente texto o termo "moda brasileira" é utilizado mais como categoria discursiva do que como realidade objetiva constituída por elementos estéticos específicos que caracterizariam a "brasilidade" da moda produzida no Brasil. Importa-nos menos saber se a moda brasileira" tem de fato materialidade histórica e estética, se é um apenas discurso ou mesmo um mito, do que pensá-la em termos de uma realidade social, no sentido em que ela tem mobilizado corações, mentes, corpos e, claro, bolsos. Como um respaldo simbólico às ações de agentes do setor de moda no país e no mundo, essa categoria tal qual usada pelos próprios atores - para afirmá-la ou criticá-la constitui, em alguma medida, parte da realidade social dos mesmos e se estende para além deles. Como bem colocado por Pierre Bourdieu (1989, 1999, etc), o fato de algo ser simbólico não faz dele menos real. Sendo assim, estamos longe de afirmar que não existe moda no Brasil. Ao contrário, nas últimas

${ }^{4}$ http://www.abit.org.br/site/noticia. Acesso em 01/09/2010. 
décadas esse setor tem se desenvolvido substancialmente no país. O que tentamos sublinhar é que por "moda brasileira" não nos restringimos a pensar a origem produtiva das mercadorias de moda, visto que, ao menos enquanto categoria discursiva, a "moda brasileira" pode ser operada hoje em qualquer lugar do mundo. Atualmente, têm surgido marcas que se declaram "francobrasileiras", "ítalo-brasileiras" e assim por diante. Essa questão mereceria um estudo detalhado, mas por hora basta dizer que o que elas têm em comum é o fato de lançar mão das imagens e representações do Brasil, operacionalizando-as no mercado global de moda. Assim, a adjetivação "brasileira" tem sido evocada tanto em relação à moda produzida no Brasil por brasileiros - seja ela para o mercado interno ou externo - quanto em referência à moda criada por agentes não- brasileiros ou em parceria com eles. Trata-se de um termo usado e operado pelos atores que constituem o setor de moda no Brasil e também por agentes que, em diálogo com ele, o ultrapassam.

\section{Sobre o decurso/discurso de pluralização da boda mundial}

Até a década de 1950, a moda era dividida entre confecção industrial e alta costura, havendo ainda produções intermediárias, como o trabalho das costureiras. Entretanto, a alta costura francesa detinha o monopólio de emitir as diretrizes para o que era vestido - ou deveria ser vestido - no mundo todo, com maiores ou menores adaptações em função das diversas condições materiais e culturais implicadas. Com as condições sociais, econômicas e culturais constituídas a partir do pós-guerra, a influência internacional do ready to wear americano e o desenvolvimento conseguinte da indústria do rebatizado prêt- $\grave{a}$ porter em diversos países, a alta costura vai aos poucos perdendo sua hegemonia diretiva e passa a ser apenas mais uma das influências presentes na determinação da moda.

Na metade da década de 1960 - ou seja, justamente quando Kenzo chega a Paris - o prêt- à-porter já era predominante. (Laver, 2002, p.265)

Gilles Lipovetsky (1987, p.145) sustenta que os anos 1960 inauguram a "moda aberta", que seria caracterizada pela multiplicação dos critérios de definição da moda. Nos anos 1960 e 1970, o "consenso estético" da alta costura teria sido pulverizado com a criação do sportswear, das modas dos jovens à margem da sociedade, dos criadores das novas marcas de prêt-à-porter e das butiques. Para o autor, o dirigismo teria dado lugar à "justaposição de estilos". A "pirâmide" da moda, cujo ápice até então havia sido a alta costura, se modifica e a rua, a juventude, a rebeldia, o exotismo, o folclore, o étnico, o tradicional, as "tribos urbanas", as modas "marginais" ganham cidadania na recém proclamada "democracia da moda". James Laver (2002, p.268) também sustenta que a década de 1960 marca o início do "pluralismo de estilos" da atualidade. Para ele, a partir desse momento as sociedades americanas e européias de tornam cada vez mais multiculturais, tal como a moda vigente em tais sociedades. 
Os usos da diversidade cultural no mercado mundial de moda: a dinâmica das identidades nacionais na globalização

O "diverso" começa a mudar de estatuto e vai ser devidamente incorporado pelas marcas de prêt-à-porter e mesmo de alta costura, a qual historicamente já se valia do "exótico" em suas criações. A valorização cultural generalizada da idéia de diversidade - analisada, por exemplo, por Renato Ortiz -, bem como a organização do setor da moda em nichos de mercado e na diferenciação de produtos levam-na a buscar o "diverso", isto é, o que seria distinto do "ocidental", identificado com o europeu-americano coetâneo. Nessa conjuntura, a moda teria deixado de ser um "reino" e, portanto, já não poderia organizar-se em torno de um único trono. Assim, a partir dos anos 1970, Londres, Milão e Nova Iorque começam a se afirmar ao lado de Paris como "capitais da moda". A hegemonia simbólica passa a ser compartilhada, o que não significa que Paris tenha perdido sua importância secular ${ }^{6}$

A atual configuração da moda em um circuito de "fashion weeks" sediadas em "capitais da moda" é relativamente recente e faz parte da composição cada vez mais complexa e organizada do setor. Desde meados do século XX, ele passa a contar com feiras têxteis, com salões de prêt-à-porter, com empresas de "prospecção de tendências", com uma imprensa destinada ao consumidor final e uma outra consagrada aos profissionais... São mecanismos de orquestração de uma cadeia cada vez mais complexa, que vai desde a indústria químico-têxtil até a distribuição e promoção das mercadorias ${ }^{7}$. Essa complexificação da organização contemporânea da moda é vista por alguns como um movimento de "democratização da moda", posto que haveria hoje muito mais agentes e muito mais "estilos", a partir os quais o indivíduo seria livre para escolher sua aparência, diferentemente do que ocorria em épocas anteriores. Além disso, a entrada de outros países no circuito mundial da moda ampliaria ainda mais tal democracia.

O pluralismo e a diversificação são componentes do discurso de praticamente todos os atores em presença. No presente trabalho, os discursos são tomados por "sintomas" 8 que indicam transformações substanciais. Nesse sentido, poderíamos arrolar sucintamente algumas das

${ }_{6}^{5}$ Renato Ortiz. "Anotações sobre o universal e a diversidade".

${ }^{6}$ Sobre a supremacia de Paris consultar Valerie Steele. Paris fashion: a cultural history. Ver ainda Rosalind H. Williams. Dream Worlds: mass consumption in late nineteenth-century France

${ }^{7}$ Quando falamos em cadeia da moda nos referimos especialmente ao setor de vestuário, mas não excluímos o setor de acessórios, composto por calçados, bolsas, cintos, jóias, bijuterias, etc. Além disso, a indústria da moda é composta atualmente por uma grande quantidade de atividades correlatas, que devem igualmente ser levadas em conta. Ainda, convém destacar que, embora não desconsideremos os vários nichos de mercado do setor, analisamos sobretudo o chamado pret-à-porter de luxo.

8 Sobre essa discussão ver a análise de Slavoj Žižek em “Como Marx inventou o sintoma?" 
mudanças percebidas como elementos de diversificação no mundo da moda.

Um deles seria a multiplicação das semanas de moda ao redor do mundo. As fashion weeks adquirem importância como agentes no mercado porque elas organizam o calendário produtivo, unindo todos os elos da cadeia em torno de datas fixas conhecidas de antemão. Elas coordenam ainda as relações entre as esferas da produção e a da comunicação de moda. Além disso, elas ajudam na distribuição, pois geralmente são acompanhadas por salões e show rooms destinados à apresentação e negociação da coleção seguinte para as empresas de varejo. De acordo com entrevista ${ }^{9}$, além de organizar a cadeia e fazer publicidade para as marcas, uma fashion week desempenha o papel de fazer publicidade para o país ou cidade que a acolhe, pois esse tipo de evento conferiria "uma idéia de liberdade e de modernidade à cidade ou população que a promove". Nas palavras da entrevistada,

[...] presque toutes le villes font de fashion week maintenant pour montrer localement et internacionalement qu'ils sont créatifs, propres et cetera. Il y a même une fashion week, j'ai vu l'autre jour, à Islamabad, un truc de fou... des rebelles, une espèce de groupe... je pense qu'ils vont tous aller en prison bientôt. Ils ont fait une fashion week à Islamabad, avec des filles maquillées comme ça [faz gesto que realça os olhos] dans des petits... terrible. C'était Islamabad ou Karachi... un truc allucinant qui ne devrait même pas exister, mais ils l'ont fait et tant mieux, good for them, parce que c'est courageux.

Mas voltemos às fashion weeks que "deveriam existir". O modelo organizacional e institucional da "semana de moda" surgiu em seus moldes atuais na França. Em 1973 a Câmara da alta costura e a Federação do prêt-à-porter dos criadores se associam e o poder público francês lhes permite a utilização de lugares públicos célebres para e exposição de coleções. (Ruppert at al, 1996, p.407). As apresentações são acompanhadas por jornalistas internacionais e compradores do mundo todo. Paralelamente, a Federação francesa do prêt-àporter feminino resolve expor conjuntamente as coleções de seus associados em lugares públicos de Paris, configurando um salão de prêt-à-porter: eis uma semana de moda, cujo formato será mais ou menos o mesmo nas capitais que formam atualmente um circuito "oficial" ou "mainstream" da moda. A primeira

${ }^{9}$ Trata-se de uma agente comercial que trabalhou anos na organização da London Fashion Week e que hoje se ocupa da inserção das modas de países emergentes no mercado europeu e americano. A entrevista foi concedida à autora no salão Paris sur Mode durante a Paris Fashion Week em 06/03/2010. 
Os usos da diversidade cultural no mercado mundial de moda: a dinâmica das identidades nacionais na globalização

manifestação da semana de Milão data de 1958, a de Londres nasce em 1983, a de Tókio tem sua primeira edição em 1985, a de Nova Iorque surge com seu formato atual em 1993 e a de São Paulo é lançada em seus moldes iniciais em $1995^{10}$.

A coordenação das datas desse circuito de fashion weeks não ocorre espontaneamente, mas é resultado de negociações entre as instituições e associações profissionais mais importantes de cada "capital mundial da moda": em Nova Iorque, o Council of Fashion Designers of America, fundado em 1962; em Londres, o British Fashion Council, fundado em 1983; em Milão, a Camera Nazionale della Moda Italiana, fundada em 1958; e em Paris, a Fédération française de la couture, du prêt-à-porter des couturiers et des créateurs de mode, cuja primeira configuração data dos idos de 1868. Em cada temporada as fashion weeks seguem a ordem em que as cidades foram citadas acima e essa organização do calendário permite aos diferentes atores da moda se deslocar de uma capital a outra sem perder os desfiles mais importantes (Godart, 2010, p. 37/38).

As "outras" devem se organizar para "caber" nesse calendário préestabelecido, sob pena de serem ignoradas pelos atores mais relevantes. E elas são muitas a alongar a maratona de cada estação. Se até 1990 elas eram organizadas apenas em Paris, Milão e Londres, na última década do século XX elas começam a surgir com mais freqüência e desde a virada do milênio foram criadas semanas de moda em quase 100 cidades, de Amsterdan a Zagreb, para irmos de $\mathrm{A}$ a $\mathrm{Z}^{11}$. Isso para não falarmos de eventos como o Capital Fashion Show, de Brasília, o Minas Trend Preview ou o Dragão Fashion Brasil, organizado em Fortaleza, as quais não entram nessa contagem.

A hegemonia das quatro grandes na definição do calendário mundial fica clara em outro momento da entrevista supracitada, quando nos informa que a Índia tem hoje duas fashion weeks principais que competem entre si: a de Nova Déli, oficial, que conta com apoio governamental, e a de Mumbai, que pertence ao grupo $\mathrm{IMG}^{12}$. Supostamente por razões econômicas, já que o mercado interno seria o mais importante para os empresários indianos, o IMG teria resolvido organizar a semana de Mumbai concomitantemente àquela de

${ }^{10}$ Interessante notar que, em virtude de formatos diversos, interrupções e inconstâncias, há várias controvérsias sobre as datas de fundação das semanas, que em geral reivindicam uma origem antiga, nos moldes do "sempre fomos uma capital da moda".

${ }^{11}$ http://en.wikipedia.org/wiki/Fashion_week. Acesso em 03/09/2010.

${ }^{12}$ O International Management Group é um importante grupo especializado em eventos, mídia, entretenimento, esportes e moda. Além de organizar outras semanas de moda, como a de Nova Iorque, eles agenciam grandes modelos e grandes atletas, como Gisele Bündchen e Tiger Woods, para citar alguns. Mais informações em http://www.imgworld.com. 
Miqueli Miquetti

Paris, o que impediu que a agente entrevistada estivesse presente na fashion week indiana, embora devesse trabalhar com a IMG. De acordo com ela,

Les indiens s'en foutent du reste du monde. Donc ils font leur fashion week pour eux. La fashion week de Bombay elle est maintenant, avec Paris. Je devais collaborer avec eux de l'IMG, mais quand ils m'ont donné les dates... 'Mais vous êtes fous ? C'est au milieu de Paris. Ça va pas. C'est emmerdant que je ne peux pas travailler avec vous, parce que je peux pas être à Bombay pendant la fashion week de Paris. Ça existe pas et en plus je travaille avec le Brésil aussi. J'aimerais bien collaborer et avec vous et avec le Brésil, mais si c'est vous ou le Brésil, ça reste le Brésil, parce que vous c'est pas possible en même temps'.

É evidente, portanto, que as mais impotantes seguem sendo as 4 iniciais, mesmo que algumas dentre as recentes sejam "emergentes", ou seja, conseguem chamar mais atenção, como a de São Paulo.

Cada uma delas busca se destacar, alcançar uma "identidade", que deve necessariamente ser calcada na diversidade dos expositores. Mas ao mesmo tempo em que buscam uma identidade específica, as "big four" se afirmam como globais e, como tais, aumentam seu prestígio. Como exemplo, podemos dizer que algumas marcas brasileiras se apresentam já há alguns anos na semana de Nova Iorque, enquanto na semana de São Paulo os desfiles costumam restringir-se às marcas nacionais. Sabe-se que a lista das marcas participantes da "agenda oficial" não é definida em função das nacionalidades das marcas e tem a ver com a maior ou menos abertura das federações e de seus respectivos mercados, com o tamanho do orçamento das empresas que é disponibilizado para desfiles, com o prestígio das marcas em questão, entre outras coisas.

Ainda assim, é curioso que as semanas brasileiras exponham marcas brasileiras e as big four acolham marcas "globais".

Na fashion week de Paris de março de 2010, que acompanhamos de perto, dos 88 desfiles "oficiais", entre os quais o da marca fundada por Kenzo, hoje de propriedade do grupo LVMH, não houve nenhum de marca brasileira. No entanto, existe na agenda oficial uma sessão desfiles "off" constituída naquela edição por 8 desfiles, dentre os quais o de um jovem estilista brasileiro estreante. Além disso, outro designer brasileiro que, segundo entrevista, construiu toda sua carreira em Paris, apresentou sua coleção na seção "avant première" da semana oficial. Ainda, houve mais 36 apresentações "extras" previstas pela organização. Isso sem contar no grande número de eventos "extra-oficiais" que ocorrem paralelamente.

Portanto, a agenda de uma fashion week é construída com oficiais e 
Os usos da diversidade cultural no mercado mundial de moda: a dinâmica das identidades nacionais na globalização

"offs". Existe uma hierarquia relativa aos horários e lugares dos desfiles. A concorrência pela atenção dos jornalistas e compradores é dividida segundo a agenda oficial, proposta pela Fédération française de la couture, du prêt-àporter des couturiers et des créateurs de mode, no caso de Paris. Também os salões são divididos hierarquicamente segundo a data e local em que ocorrem, podendo ser ou não parte da semana "oficial". Trata-se de uma operação de legitimação mútua em que marcas e salões se legitimam reciprocamente. E, em certos casos, se deslegitimam mutuamente. Como tivemos chance de presenciar, as empresas que já participaram dos salões que antecedem à fashion week parisiense são aconselhadas a não dar essa informação aos compradores que as procuram quando as mesmas são "promovidas" a participar de salões simultâneos a ela. Para quem expõe em março e/ou outubro nos arredores do Jardin de Tuilleries durante as edições da fashion week, o fato de ter exposto em janeiro e/ou setembro na Porte de Versailles é motivo de um certo embaraço. $\mathrm{O}$ circuito não-oficial de cada semana parece existir em oposição e complementaridade ao oficial, o qual, por sua vez, é mais valorizado pela existência daquele.

As fashion weeks, como os salões, operam com uma espécie de filtro: elas precisam se basear na diversidade de marcas e estilistas, mas essa diversidade é selecionada de acordo com diretrizes que precisam ser comuns, em prol da organização, da "identidade" e da qualidade da semana, do prestígio do evento, do sucesso dos negócios... E ao mesmo tempo em que promovem a diversidade de expositores, legitimando-os, excluem aqueles que não estão aptos a participar, por mais diversos que possam ser. A diferenciação deve ter lugar na moda, mas a divulgação e a promoção de algumas diferenças implicam também em relegar certas "diferenças" ao esquecimento.

Ademais, a grande maioria das fashion weeks recentes se insere nesse contexto de "pluralização" da moda mundial e, nesse sentido, elas fazem parte de seu funcionamento, porém, não conseguem se afirmar globalmente enquanto centros de moda legítimos. Talvez a existência dessas manifestações consideradas "locais" legitime ainda mais as já consagradas. São manifestações que parecem se relacionar mútua e contraditoriamente: as semanas "locais" devem expor local e globalmente sua "diversidade", mas sua legitimidade é emprestada do modelo das consagradas. E, pelo fato mesmo envergarem o estatuto de "locais", elas fazem com que as "globais' pareçam ainda mais globais e, por conseguinte, ainda mais legítimas.

Outros exemplos da "pluralização" da moda, para citar brevemente, seriam a internacionalização dos salões de moda, tanto no sentido dos expositores quanto dos visitantes; a implantação desses salões em países como o Brasil; o surgimento do setor da moda social e ecologicamente "sustentável", o qual, em geral, implica a participação dos países do chamado "global south"13 e ainda uma mudança no funcionamento das empresas de "prospecção e consultoria de tendências". ". No momento de sua criação, estas se propunham a dizer,

${ }^{13}$ Nos referimos ao termos tal como empregado por Saskia Sassen no livro Territory, authority, rights: from medieval to global assemblages. 
fixadas nos grandes centros de moda, sobretudo em Paris, quais seriam as tendências mundiais das coleções seguintes.

Atualmente essas empresas continuam desempenhando esse papel, mas concorrem por uma espécie de "capital de internacionalidade", pois assim como ocorre com os salões de moda, quanto mais internacionais elas se advogam, mais valorizadas elas são. Desse modo, elas buscam sua legitimidade espalhando agentes ao redor do globo para pesquisarem as tendências mais diversas possíveis. No entanto, estas seriam gerenciadas por determinadas agências, cujas sedes permanecem em cidades como Paris, Londres e Nova Iorque, onde a "triagem" da diversidade é realizada. Embora resulte de ações sociais e, portanto, coletivas - e não de um complô de meia dúzia de poderosos -, o funcionamento da moda mundial é dotado de "mecanismos de coordenação" operados por agências específicas (Godart, 2010, p.54-55). A coordenação da maior diversidade possível parece ser a condição de funcionamento e a base que legitima a atividade dessas agências, as quais, tal como nos indicam as reflexões de Bourdieu sobre "a produção da crença" (2002), seriam ao mesmo tempo enunciadoras e criadoras de tendências.

Além disso, com a globalização das "grandes marcas" aglutinadas em torno dos conglomerados de luxo ${ }^{14}$ e ainda das cadeias da chamada fast fashion, a moda passa a fazer parte do cotidiano de muito mais pessoas que fazia anteriormente. As grandes cidades do mundo hoje oferecem igualmente Chanel e Louis Vuitton, Zara e C\&A, de maneira que esses nomes passam a fazer parte da rotina das pessoas que vivem em um espaço internacional-popular povoado por símbolos mundializados.

Torna-se patente que, ao mesmo tempo em que a moda passa a fazer parte da vida de cada vez mais pessoas e que ocorre a entrada de novos agentes e regiões no setor, nós assistimos a um processo de concentração, com a formação dos grandes dos conglomerados de luxo e o aumento do poder das grandes cadeias de produção e distribuição que "deslocalizam" o processo produtivo, "relocalizando-o" nos lugares do mundo cujos salários são mais baixos e as leis trabalhistas e ambientais mais "flexíveis". ${ }^{15}$

Ao mesmo tempo em que as empresas de tendências espalham agentes pelo mundo, elas mantêm o poder de orquestrar a diversidade recolhida constantemente. Ao mesmo tempo em que novas semanas de moda pululam ao redor do mundo, as estabelecidas garantem sua hegemonia. Ao mesmo tempo em que o Paquistão ou a Índia passam a ter semanas de moda e que o Brasil passa a concorrer para a criação de uma "moda brasileira", o made in France e o made in Italy fazem sentir a sua força nos bilhões de dólares que constam nas tabelas anuais de faturamento dos conglomerados de luxo sediados nesses países.

${ }^{14}$ Consultar Dana Thomas. Deluxe: como o luxo perdeu o brilho. Os bastidores da atual indústria da moda; e ainda Jean Castarede. O luxo: o segredo dos produtos mais desejados do mundo.

15 Paulo Fernandes Keller "Economia global e novas formas de organização da produção na cadeia têxtil- confecções". 
Nota-se, portanto, que a diversificação de produtos e a pluralização de atores em presença na moda contemporânea seriam acompanhadas pelo surgimento de mecanismos de coordenação, os quais seriam da alçada de poucas instâncias, como grandes feiras têxteis, semanas e salões de moda organizados por algumas instituições importantes e grandes empresas de eventos, certas agências de prospecção de tendências, grandes conglomerados e certos veículos midiáticos consagrados. Mas, se por um lado, esse processo traz consigo certa homogeneização mundial dos modos de vestir e uma concentração de capital econômico e simbólico, por outro lado, surgem novas dinâmicas no circuito de legitimação da moda. Em tempos de des-localização da produção, nada mais valorizado que o made in France. Numerosas são as iniciativas públicas e/ou privadas que buscam lembrar o mundo disso. Elas são levadas a cabo por federações, associações, órgãos de promoção de exportação, embaixadas, entre outros interessados no prestígio do made-in-país-que-pagaseguro-desemprego. No entanto, essa resignificação simbólica da idéia de nação ou de país de origem vai além das ações de defesa de mercado de países consagrados no setor. Quando a noção de diversidade torna-se a vedete da vez, surgem espaços (específicos e determinados, é bom lembrar) para países e regiões até então excluídos do mapa da moda.

Queremos sublinhar que nossas referências ao made in France ou ao made in Brazil são feitas mais em relação ao patamar da modernidade-mundo do que ao plano geocultural. Tal como sugere Ortiz ao analisar a relação da alta-costura com o "japonismo", o universo do consumo é regido antes pela diferença de classe e pelo poder aquisitivo do que pelas posições geográficas. Ele toma o exemplo sugestivo das vestimentas: [...] a relação quimono - calçapaletó não mais ilustra uma oposição entre o Japão e o Ocidente, mas muito mais uma oposição entre um Japão tradicional e outro moderno."(2000, p.142). Nos termos de Marc Augé, Ortiz indica que a mundialização da cultura desloca o "lugar antropológico"16 para o "não-lugar": as lojas de perfumes são semelhantes em todos os aeroportos do planeta. Mas isso não impede que as marcas sejam predominantemente de origem francesa. Contudo, a "francesidade" dos perfumes não é definida nacionalmente, ao contrário: ela é valorativa em relação a outros produtos semelhantes/distintos cujo valor também é definido de maneira relacional no espaço- tempo da modernidademundo. Citemos uma vez mais Ortiz quando ele afirma que "no mercado da moda o que interessa não são as oposições geopolíticas, mas a griffes. A T- shirt de origem chinesa comprada num supermercado de periferia não se opõe ao cosmético francês em termos de Ocidente/Oriente ou de França/China. Os termos se contrapõem enquanto consumo popular e consumo diferenciado". (2000, p. 147). Não obstante, isso não torna um suposto perfume chinês tão valorizado quanto um perfume francês. Tampouco isso faz com que os

16 Segundo Ortiz, (2000, p.137), para Marc Augé, o lugar antropológico é um território geográfico investido de sentido, um substrato material investido de sentido simbólico. 
perfumes produzidos sob a marca Kenzo sejam menos valiosos do que os perfumes Chanel apenas em razão da origem dos fundadores das respectivas marcas.

O mercado da moda estabelece uma negociação complexa no processo de legitimação das marcas. Atualmente, a origem ainda é levada em consideração, mas de acordo com uma reconfiguração simbólica dos espaços que toma corpo no processo de globalização. Na atualidade, o não-lugar, ou, antes, o internacional-popular é valorizado como representante da modernidade-mundo, mas, ao mesmo tempo e como fenômeno possivelmente correlato, os "lugares" passam a ser valorizados como representantes da tradição a ser preservada ou resgatada ${ }^{17}$. Por contraditório que isso possa parecer, o nacional-popular, considerado como uma espécie de repositório de diversidade em tempos de mundialização, parece ganhar uma edição global ${ }^{18}$. Assim, junto com a valorização da diversidade sobre a qual versávamos acima, assistimos à uma certa positivação daquilo que é "local", freqüentemente relacionado ao "autêntico" e/ou ao "diverso". É nessa conjuntura que a moda produzida no Brasil vai buscar legitimar-se no espaço mundial. E enquanto "brasileira" que ela vai negociar seu caráter local, nacional ou global no mercado mundial de moda.

\section{Sobre o decurso/discurso de criação da "moda brasileira"}

O recrudescimento da idéia de uma "moda nacional" deve ser analisado com este contexto mais amplo em mente, visto que tal idéia ganha novo significado ante a conjuntura de globalização, sendo recondicionada por ela e, ao mesmo tempo, caracterizando-a. Nosso propósito com essa afirmação não é afirmar que a idéia de "moda brasileira" surge apenas e tão somente na contemporaneidade. Sabemos que ela é tributária de transformações culturais e materiais que remontam pelo menos ao desenvolvimento da indústria têxtil brasileira em razão do desabastecimento mundial de têxteis causado pelas duas grandes guerras mundiais do século XX. Nós não ignoramos as investidas das companhias têxteis como a Bangu, a Rhodia e a Matarazzo para promover a aceitação de sua produção para um público que menosprezava o produto nacional, nem subestimamos o papel da

${ }^{17}$ Esse processo tem algumas semelhanças com o movimento de resgate/criação de tradições ocorrido na Europa do século XIX, na conjuntura de industrialização. Sobre isso ver o interessante estudo de Anne- Marie Thiesse em La création des identiés nationales. Europe XVIIIe - XXe siècle. Ver ainda os estudos organizados por Eric Hobsbawm e Terence Ranger em A invenção das tradições.

18 Renato Ortiz trabalha com as noções de cultura nacional popular e internacional-popular em A moderna tradição brasileira. Cultura Brasileira e indústria cultural. Sobre o assunto, consultar também, do mesmo autor, Mundialização e cultura.

Latitude, vol. 3, n¹, pp.96-124, 2009. 
Os usos da diversidade cultural no mercado mundial de moda: a dinâmica das identidades nacionais na globalização

FENIT, a Feira Nacional da Indústria Têxtil, criada em 1958 com o propósito de conjugar a cadeia nacional de têxteis e confecções, então em formação. Também não nos esquecemos das iniciativas de Lívio Rangan enquanto publicitário da Rhodia ${ }^{19}$ e, anteriormente, de Pietro Maria Bardi, então Diretor do Museu de Arte (atual MASP), de promover "eventos que contribuíssem para a constituição e o estímulo de uma "moda brasileira'" (NEIRA, 2010). Tampouco nos é indiferente o papel de Alceu Penna ${ }^{20}$ e de Carmen Miranda ${ }^{21}$ na construção do ideário da moda nacional, assim como o destaque de costureiros e estilistas como, entre outros, Dener ${ }^{22}$ e Zuzu Angel ${ }^{23}$.

Lembramos ainda da importância para a formação da noção de "moda brasileira" da constituição dos grupos estaduais ou "regionais" de moda e o surgimento de marcas nacionais de prêt-à-porter a partir do final dos anos 1970. Em fins da década de 1980, quando começa a crescer tanto a crítica à cópia dos modelos e das tendências em voga na Europa e nos Estados Unidos quanto a preocupação com a criação nacional, os cursos superiores de moda surgem com o objetivo de profissionalizar a moda e conferir a ela uma "identidade", de forma que a discussão sobre a "moda brasileira" ganha mais um campo onde florescer. O desenvolvimento da imprensa de moda no Brasil, com o surgimento de revistas, do jornalismo e da crítica especializada, também teve papel nesse movimento.

Os 1990 trazem consigo os primeiros destaques de estilistas brasileiros no exterior e os holofotes se viram para as modelos brasileiras. A modelo Gisele Bündchen teria desempenhado, segundo vários profissionais e mesmo estudiosos da moda, papel fundamental na afirmação internacional de uma "moda brasileira". Mas a última década do século XX faz mais do que revelar celebridades. Aliás, estas somente têm espaço mediante uma reestruturação da moda produzida no Brasil. Nos anos 1990, com a abertura do mercado brasileiro, a cadeia têxtil do país teve de fazer face à concorrência tanto das mercadorias asiáticas com baixos preços quanto das marcas européias e norte-americanas consagradas, que passaram a entrar com mais facilidade no mercado nacional. É nesse momento de reorganização do setor que se desenvolve com força inédita a idéia de se desenvolver uma "moda brasileira"

\footnotetext{
${ }^{19}$ Sobre a história da Rhodia no Brasil ver Maria Cláudia Bonadio, O fio sintético é um show! O trabalho também possui informações interessantes sobe a Fenit e sobre a moda no Brasil nas décadas de 60 e 70.

${ }^{20}$ Consultar Maria Claudia Bonadio e Maria Eduarda Araujo Guimarães. "Alceu Penna e a construção de um estilo Brasileiro: modas e figurinos".

${ }^{21}$ Sobre isso ver Tânia da Costa Garcia. O "it" verde e amarelo de Carmen Miranda.

${ }^{22}$ Carlos Dória. Bordado da fama: uma biografia de Dener.

${ }^{23}$ http://www.zuzuangel.com.br. Consultar as dissertações de mestrado de Dayse Marques. Zuzu Angel: a identidade cultural brasileira através da moda e de Priscila Andrade Silva. A moda de Zuzu Angel e o campo do design.
} 
como diferencial competitivo. Portanto, a idéia de desenvolver uma moda com caráter nacional é re-evocada justamente quando as relações com o mercado mundial se estreitam. E, por ressurgir em uma nova conjuntura, ela apresentará algumas especificidades com relação às formas com as quais ela se apresentou em momentos anteriores à globalização.

Essa relação inextricável com a conjuntura mundial fica evidente na formação da primeira fashion week do país, organizada em São Paulo. O evento embrião da semana foi o Phytoervas Fashion, lançado em fevereiro de 1994 e já organizado por Paulo Borges, que viria a se tornar o organizador das duas semanas de moda mais importantes do país. Em julho de 1996 surge o MorumbiFashion Brasil, ao qual agrega-se o subtítulo "Calendário Oficial da Moda". Em janeiro de 2001 o evento passa por outro rearranjo e começa a ser realizado na Fundação Bienal, no Parque do Ibirapuera, onde opera até hoje bianualmente, acompanhando o ritmo de todos os grandes mercados de moda do mundo, embora com estações opostas com relação ao hemisfério norte. Consolida-se assim a São Paulo Fashion Week - Calendário Oficial da Moda Brasileira $^{24}$.

O título do evento pode nos dizer algumas coisas interessantes. Segundo o próprio Paulo Borges, "o novo subtítulo São Paulo Fashion Week veio da percepção da forma como a imprensa internacional se dirigia ao evento. Assim como nos demais centros de moda do mundo, seus calendários levam o nome da cidade onde eles acontecem". (Borges e Bianco, 2002, p.1002). Seu último sobrenome, "Calendário Oficial da Moda Brasileira", tampouco é casual ou gratuito. O SPFW surge em um momento em que a identidade da moda produzida no Brasil torna-se o foco das discussões. Elas ganham fôlego quando as supostas manifestações identidade e/ou diversidade cultural passam a ser especialmente promovidas no mercado mundial de moda. É assim que a semana de moda do Brasil pode fazer sentido mundialmente, como é assim também que essa semana só tem razão de ser se for o porta-voz da "moda brasileira", mas para um mercado ao mesmo tempo nacional e global. Trata-se da afirmação de uma identidade nacional no contexto em que ela adquire caráter global. A semana paulistana, embora tenha adquirido características próprias e se tornado referência em termos de organização a ponto de fazer inveja ao nipônico Kenzo, que afirma invejá-la "pelo comprometimento das pessoas e pela organização do evento, pelo espaço, com desfiles de nível mundial, internacional" 25 , começou como um projeto de 30 anos que tinha como modelo e horizonte o caso de sucesso italiano ${ }^{26}$. O modelo é europeu, o objetivo é a consagração mundial, mas a moda a ser difundida é a brasileira.

Essa situação aparentemente contraditória torna-se ainda mais evidente quando nos debruçamos sobre a situação do mercado de têxteis, de confecções e de moda

\footnotetext{
${ }^{24}$ Sobre a história do "calendário oficial" ver Paulo Borges e Giovanni Bianco. O Brasil na Moda.

${ }^{25}$ Palestra SENAC 21/06/08

${ }^{26}$ Palestra conferida por Paulo Borges em 09/11/2008.
} 
no Brasil a partir dos anos 2000. Atualmente, cerca de $94 \%$ de tudo o que o Brasil produz em termos de têxtil e de moda é consumido no próprio mercado interno ${ }^{27}$. No entanto, desde a metade da década, começam a surgir projetos públicos e/ou privados que visam "a internacionalização da moda brasileira". Eles são levados a cabo por instituições como a Associação brasileira de indústria têxtil e confeç̧ão (ABIT) e a Associação brasileira de estilistas (ABEST), em parceria com a Agência brasileira de promoção de exportação e investimentos (Apex-Brasil). Na situação de globalização, a aquisição da legitimidade no mercado interno - que permanece o mais importante para as empresas brasileiras - parece passar por um circuito mundial de legitimação, para usar os termos (atualizados) de Pierre Bourdieu. Nesse sentido, a "identidade da moda brasileira" passa a ser buscada e discursada no momento de mostrá-la ao mundo. Atualmente, as marcas nacionais competem, no próprio mercado doméstico, com marcas consagradas mundialmente, o que as leva a buscar reconhecimento mundial, mesmo que seja para operacionalizá-lo internamente. Contudo, as eleições de entrada na "democracia da moda mundial" são disputadíssimas. Nesse páreo, a campanha do Brasil deve passar pela promessa de uma moda "brasileira". Portanto, a situação da moda do Brasil se configura de uma maneira bastante particular, visto que para alcançar reconhecimento no mercado nacional, é preciso ser internacional, ou, ainda, global, mas, para ser aceito no circuito mundial, é preciso oferecer uma moda nacional, local... enfim, diversa.

Assim, a média de exportação das empresas exportadoras associadas à Abest, segundo seu presidente 28 , é de $8 \%$. De acordo com entrevistas feitas pela autora com diversas empresas que exportam em associação com a Abit, a média das exportações fica entre 5 e $15 \%$. Ainda que economicamente esses números não sejam muito expressivos, essas empresas parecem buscar o mercado internacional para adquirir uma espécie de selo de qualidade a exibir no mercado nacional. A participação de salões nos centros de moda historicamente consagrados seria importante para legitimar as marcas nacionais na competição estabelecida tanto com outras marcas nacionais quanto com marcas estrangeiras ou "mundiais" presentes no próprio mercado interno. É discurso corrente entre os atores do setor que a exportação "prepararia" as empresas para a concorrência e que uma marca apta a exportar, sobretudo para a Europa, os EUA e o Japão, estaria apta a enfrentar qualquer mercado, inclusive o brasileiro. A exportação dotaria as empresas de um "padrão exportação" que seria levado em conta pelos consumidores patrícios.

Existem, no entanto, outras razões pelas quais as empresas e instituições empreendem iniciativas com vistas ao mercado externo: o fato de ser uma marca "exportadora" aumentaria o valor da marca na eventualidade de vendê-la para os grupos de moda em formação no país; para marcas que trabalham com produtos específicos para o verão, o fato de exportar

\footnotetext{
${ }^{27}$ Segundo dados da Associação Brasileira da Indústria Têxtil e de Confecções ABIT

${ }^{28}$ Entrevista concedida à autora durante a fashion week de Paris.
} 
ajudaria ainda quanto à sazonalidade desse mercado, visto que o verão do hemisfério norte ocorre quando as vendas no mercado nacional estão em baixa; outra razão citada como evidente foi a abertura de novos mercados, já que as marcas de prêt-à-porter de luxo têm como alvo pequenos nichos, que podem ser multiplicados com a venda para outros lugares do mundo.

Pensando em um âmbito mais amplo, a exportação de moda, ou seja, de produtos manufaturados de "alto valor agregado", é importante porque a balança comercial do setor têxtil é deficitária no país ${ }^{29}$. Além disso, ela auxiliaria na criação ou consolidação de uma imagem positiva para o Brasil, donde os incentivos da parte de agências governamentais. Além dessas razões de ordem econômica e política, cabe dizer que o ethos dos criadores de moda parece impeli-los à busca do reconhecimento mundial de suas criações.

Esses são alguns dos motivos pelos quais o mercado global se torna um objetivo a ser alcançado pelas empresas e instituições brasileiras. Mas para tanto, é preciso que essa moda seja bem vinda no mercado internacional e é por isso que ela se faz ver em salões na Europa e nas fashion weeks americanas, com investimento próprio e com dinheiro público ${ }^{30}$. E quais seriam os atrativos atuais da moda produzida no Brasil? Ela encarnaria a diversidade. O Brasil parece ser visto hoje como uma espécie de guardião de diversidade cultural e natural e, por perceberem isso, os atores do setor no Brasil buscam capitalizar essa imagem mundialmente. Na mesma direção, os agentes da moda mundial passam a se interessar pelo Brasil. Claro que as dimensões do mercado brasileiro, a ascensão da economia nacional e o considerável desenvolvimento do setor de moda no país nas últimas décadas são fatores determinantes. Porém, o fato de conter em si um "potencial de diversidade" é tudo menos insignificante no movimento de inserção do Brasil - ou de suas representações no mercado mundial de moda. Vejamos isso mais de perto.

O mundo inventa um Brasil e o Brasil se reinventa para o mundo: a dinâmica das identidades quando a diversidade se torna valor no mercado

\footnotetext{
${ }^{29}$ Segundo entrevista concedida à autora pelo gerente do programa Texbrasil da Abit e com os dados disponíveis no website da instituição.

${ }^{30}$ Ligada ao Ministério de Desenvolvimento, Indústria e Comércio, a ApexBrasil, agência que financia parte dos programas de exportação das empresas nacionais de moda, é mantida com fundos provenientes de tributos federais.
} 
Os usos da diversidade cultural no mercado mundial de moda: a dinâmica das identidades nacionais na globalização

\section{mundial de moda}

No início do processo produtivo da indústria da moda, existem salões têxteis. O mais importante deles é o Première Vision Pluriel, organizado bianualmente em Paris. A sede da empresa organizadora é francesa, mas atualmente ela conta com escritórios em várias partes do mundo e organiza eventos em cidades importantes para o setor. Cada edição parisiense recebe cerca 1.500 expositores de 50 nacionalidades e cerca de 50.000 visitantes profissionais vindos de mais de 100 países. Quando a PV era fechada aos expositores não europeus, as empresas têxteis brasileiras que queriam exportar participavam da Texworld, feira menos bem conceituada em razão da origem majoritariamente asiática das empresas expositoras ${ }^{31}$. Hoje as empresas brasileiras já não participam dela como expositoras, fato que os representantes da Abit têm prazer em anunciar ${ }^{32}$. Além disso, a mesma Première Vision que anteriormente vetava a participação brasileira em seus eventos realizou, em "joint venture" com uma empresa brasileira, a primeira edição da feira em São Paulo em julho de 2009. Desde então, a Première Brasil tem sido organizada semestralmente na capital paulista ${ }^{33}$.

Antes disso, em 2008, o diretor geral da feira veio à cidade, onde afirmou que o Brasil deve ser um "criador", "iniciador" e não um "seguidor" de moda. Para tanto, a moda do Brasil deveria lançar mão da "criatividade brasileira, que nós sabemos que é original, que se inspira em uma cultura popular". Ele afirma ainda que a Europa teria muito a aprender com o Brasil e que "é todo o hemisfério norte que está se inspirando no Brasil e não o contrário" ${ }^{\prime 34}$. Parece tratar-se de uma redescoberta do Brasil.

Não sejamos ingênuos, o país não se tornou um destino privilegiado apenas por ser considerado um país "criativo" ou detentor de uma "cultura

\footnotetext{
${ }^{31}$ Na edição de setembro de 2010, de um total de 700 empresas expositoras de 29 países, 383 eram chinesas, 79 turcas, 69 de Taiwan, 69 indianas, 42 de Hong Kong e 26 da Tailândia. Como contraponto, basta citar que havia uma empresa austríaca, uma belga, 2 do Reino Unido, 2 americanas e 5 alemãs. Disponível em http://texworld.messefrankfurt.com/paris/en/visitors/exhibitorresearch.html.

Acesso em 06/09/2010. Para efeito de comparação, das 1500 empresas expositoras da edição de setembro de 2010 da Première Vision Pluriel, apenas 9 são chinesas. Disponível em http://www.premierevision-pluriel.com. Acesso em 06/09/2010.
}

32 Conforme entrevista concedida à autora pelo superintendente da Abit durante a edição de setembro de 2009 da Première Vision Paris.

${ }^{33}$ http://www.premierebrasil.biz/en/default.aspx. Acesso em 06/09/2010.

${ }^{34}$ Palestra conferida em São Paulo em 29-07-2008. 
Miqueli Miquetti

particular". Afinal, essa fama não data de 2008 e o incentivo atual dessa idéia por órgãos públicos e privados não faz dela algo recente. Isso não diminui a importância do fato de que atualmente um país "mestiço" contém em si algo positivo, ligado à diversidade e à criatividade e, portanto, relevante para os negócios da era da "economia criativa". Não pretendemos explicar esse interesse mundial pelo Brasil apenas por meio de elementos "estéticos" ou discursivos. O país passa a ser apreendido como uma grande economia com um grande mercado potencial e, além disso, pode funcionar como via de acesso aos mercados da América do Sul. Assim, para entendermos o interesse das feiras têxteis e salões de moda no mercado brasileiro devemos imperativamente levar em conta o fator econômico. O responsável pela área de moda da Apex-Brasil não nos deixaria esquecer:

[...] a grande novidade, quando eu estive lá ano passado [nos salões de Paris], é que veio o diretor da feira falar comigo, veio a presidente da federação francesa falar comigo. Eles vêem hoje a importância do Brasil. Agora na São Paulo Fashion Week, a Ubifrance, que é a Apex da França, me convidou pra uma reunião com os diretores e os presidentes das feiras francesas que vão vir ao Brasil. Porque que eles tão vindo ao Brasil? Não é porque a gente é bonitinho não. É porque nós temos um mercado e eles estão percebendo que nós estamos nas feiras e que muitos outros países não estão mais em função da crise. Então é tudo negócio[... $]^{35}$.

O fator imediatamente econômico é inegável. Contudo, é importante também que esses salões estejam presentes nas partes do mundo "que contam" porque eles competem entre si por um "capital de internacionalidade" ou de "globalidade" que os torna célebres e valiosos. O International Lounge da edição parisiense da PV exibe orgulhosamente seus panfletos dos próximos eventos internacionais, sempre organizados, por motivos óbvios, nos maiores mercados têxteis do planeta: Première Vision Preview New York, Première Vision China Shangai Beijing, Première Vision Moscou, Première Vision Tokyo e, agora, Première Brasil, assim mesmo, com o nome deste país escrito em português ${ }^{36}$.

Passando das feiras têxteis aos salões de prêt-à-porter, é possível perceber esse mesmo movimento de valorização do Brasil. O delegado do Salão Prêt-à-Porter Paris, responsável pelo Brasil e pela América do Sul afirma

35 Entrevista concedida à autora em evento da Apex-Brasil em São Paulo em 17/05/2010.

${ }^{36}$ Flyer distribuído no International Lounge da Première Vision Paris em setembro de 2009.

Latitude, vol. 3, n¹, pp.96-124, 2009. 
Os usos da diversidade cultural no mercado mundial de moda: a dinâmica das identidades nacionais na globalização

que o Brasil é um mercado que o mundo inteiro procura hoje tanto por razões econômicas, já que o Brasil "é quase um continente" quanto pela "metissage que nós temos", o nosso "conhecimento de várias culturas". Ele diz que "são poucos os países que têm essa metissage que a gente tem e isso é super bom, é super valorizado". E continua:

$\mathrm{Eu}$ acredito que o mercado europeu, quando ele compra roupa brasileira, ele não compra só a peça, ele compra um imaginário Brasil, esse jogo de cintura, essa leveza, como eles dizem... Nós falamos cantado... Então compra a peça como se ele tivesse fazendo uma viagem imaginária pro Brasil.

Quando questionado sobre necessidade de adaptação das roupas brasileiras ao mercado europeu, ele afirma que

[...] nós temos o nosso folclore, coisas maravilhosas, só que você não vai vender aquela mesma blusinha de renda com aquele bordado que a bisavó já teve, que a vó teve, a mãe teve e vim com aquilo, porque as pessoas não agüentam mais aquilo. Então você utiliza - e esse é o trabalho que a Abit ta fazendo muito bem feito detalhes do nosso artesanato, do nosso savoir faire, mas com moda, com o volume certo... nas cores de moda. A não ser moda praia, que o Brasil é capital mundial do lançamento de moda praia e isso todo mundo fala e isso é um reconhecimento mundial do Brasil ${ }^{37}$.

A receita seria adicionar ao universal da moda um toque de "capital Brasil" 38, isto é, as cores e os volumes "certos". Tamanha é a sua confiança no potencial do Brasil que ele afirma que um diferencial competitivo do salão por ele representado é o fato de ser o maior expositor de marcas brasileiras e aquele que primeiro as teria aceitado em Paris.

Buscamos ouvir também a responsável pelo Brasil e América Latina dos salões organizados pelo grupo WSN Développement, concorrentes do Prêt-àPorter Paris. Ela parece estar de acordo sobre o trunfo brasileiro nesses salões ao afirmar que "O Brasil enriquece o salão com a criatividade, com certeza. [...]

${ }^{37}$ Entrevista concedida à autora no escritório do agente em Paris em 10/03/2010.

38 Conforme a utilização do termo por Débora Krischke Leitão em "Nós, os outros: construção do exótico e consumo de moda brasileira na França". Consultar também a tese de doutorado da autora: Brasil à moda da casa: imagens da nação na moda brasileira contemporânea. 
Miqueli Miquetti

Isso enriquece o salão: marcas de qualidade com criatividade. Brasileiro tem muito disso, né?"39, pergunta ela, sem necessidade de resposta.

A agente comercial mundial - exceto para o mercado japonês - da Abest também afirma a importância atual do Brasil, mas em outros termos. Para ela, a moda do país é importante na Europa tal como já foram importantes os japoneses, os belgas ou os italianos. A moda funcionaria com "ondas" e existiriam apostas de que o Brasil traria a "nouvelle vague" da moda mundial. Ela afirma que o Brasil traz "algo de novo, de fresco, de inédito" para o mercado e, nesse sentido, alimentaria o circuito por ter o caráter de "novidade", condição sine qua non de existência da moda.

O presidente da Abest parece partilhar a opinião de que "no momento atual há uma receptividade muito interessante do Brasil pelo mundo" ${ }^{40}$. Ele também aposta no "frescor" como um atributo positivo da "moda brasileira". Entretanto, ele pretende que a essa valorização seja mais que um "boom" característico do funcionamento regular da moda. Até pela posição que ocupa, ele a postula como algo que deve ser duradouro. Ao falar da fundação da Abest, ele indica que a idéia inicial da instituição era "mostrar o brazilian lifestyle para o mundo" e seu objetivo era "promover e fortalecer a moda nacional no

mercado externo", bem como "investir e nos fortificar ainda mais em solo nacional, atuando nas duas frentes de forma intensa". Ao dar voz à empreitada simultânea de formação e internacionalização da "moda brasileira", ele afirma que os salões europeus buscariam expositores brasileiros porque seria importante vender o espaço do salão, especialmente em tempos de crise, quando as empresas européias passam por dificuldades financeiras. Outro atrativo da "moda brasileira" para os salões e compradores seria o seguinte:

[...] o buyer se encanta com a criação nacional, com o nosso brazilian lifestyle. Oferecemos muito mais do que roupas, jóias e sapatos com design, qualidade ou identidade, nossos produtos carregam uma síntese do mundo. A moda brasileira não é folclórica, nem regional, é despojada, chique, casual, com tempero e linguagem global. Na verdade, ela nada mais é do que o reflexo da nossa riqueza e miscigenação cultural e racial. ${ }^{41}$

${ }^{39}$ Entrevista concedida à autora durante os salões Who's Next e Première Classe em 23/01/2010.

40 Entrevista concedida à autora em 07/03/2010 no salão Paris sur Mode e Tranoï, ambos durante a Paris Fashion Week.

41 Entrevista concedida à Henriete Mirrione. Disponível em www.abest.com.br, acesso em 15/12/2007.

Latitude, vol. 3, n¹, pp.96-124, 2009. 
Os usos da diversidade cultural no mercado mundial de moda: a dinâmica das identidades nacionais na globalização

Essa visão elogiosa da idéia de país miscigenado é partilhada pelo gestor de projetos de exportação de moda da Apex-Brasil. Para ele, tudo que era considerado negativo - a nossa "mestiçagem", o nosso "jeitinho" -

passaria hoje a ter conotação positiva e a moda do Brasil só teria a ganhar com isso.

Em suas palavras:

Acho que antigamente era mal visto...essa visão do mestiço. Hoje não. A gente já começa a perceber as pessoas vendo a gente como o mundo. Nós temos tudo aqui. As pessoas ficam pasmas com o fato de ter de tudo. Tudo que era visto de forma negativa se transformou em algo único. É incrível isso. O mundo mudou muito. Essa globalização trouxe isso, trouxe uma visão de Brasil único.

Também o gerente do programa Texbrasil da Abit afirma que "a brasilidade e a diversidade brasileira têm feito a diferença" nos projetos de exportação de moda:

[...] o Brasil é muito amplo, a diversidade cultural que fez o Brasil nos trouxe uma criatividade muito forte e uma coisa muito clara: o que o comprador internacional não quer. Ele não quer que a gente vá pra uma feira de prêt-à-porter, uma Première Vision, e copie o que vemos lá, porque isso ele compra da China, da Turquia, do Vietnan, ele compra ali dentro, não precisa vir pra cá. [...] A brasilidade vêm com a originalidade. Eles querem coisas originais, embora tenha sido inspirado no que está se dizendo no mundo. Tem que se respeitar a inspiração, mas transformar essa inspiração em produtos genuinamente brasileiros" 42

A receita é repetida: junte-se ao que "está se dizendo no mundo" uma pitada da mais genuína criatividade brasileira.

A responsável pela comunicação da empresa Luminosidade, empresa que organiza a São Paulo Fashion Week e ainda a semana de moda do Rio, nos informa sobre outra estratégia de internacionalização da "moda brasileira", que em geral também é apoiada pela Apex-Brasil e ganha o nome de "projeto comprador". Trata-se de convidar compradores e jornalistas estrangeiros, sobretudo da Europa e dos EUA para conhecer a moda do país

${ }^{42}$ Entrevista concedida à autora em 19/11/2008 na sede da Abit em São Paulo. 
Miqueli Miquetti

no próprio país. Para ela, quando os compradores e jornalistas visitam o Brasil, eles são envolvidos no que ela chama de "cara brasileira".

Você envolve o estrangeiro com aquilo a gente tem de melhor, com nossa forma de receber, como nosso acolhimento, essas são características do Brasil que tem reflexos na moda. Não tá dissociado. Agora se eu levo essa moda sem qualquer contexto cultural, sem qualquer contexto de pais, no sentido de origem, de raiz, eu vou pra lá [para a Europa e os EUA] como órfão, como mais um. O fato de ser o Brasil é totalmente relevante, porque nós temos de fato uma diversidade e isso a pessoa só vê quando está aqui.[...] Se eu trago o jornalista pra cá e mostro 50 desfiles de A a Z, eu estou mostrando que é de verdade, que a moda brasileira é construída com base nessa diversidade. $\mathrm{E}$ tem que ser, porque nós somos um continente, com várias regiões. $\mathrm{O}$ americano, por exemplo, apesar de ser um continente, ele não incorporou essa diversidade como nós". [E continua] Acho que a gente tem a nosso favor o fato de que a gente tem uma imagem muito simpática lá fora, apesar de todas as nossas questões de carências básicas, a gente é simpático pra eles. Eles acham o povo simpático, eles acham essa forma que a gente encontrou de fazer um caldeirão de tudo e recriar, essa coisa antropofágica, tropicalista nossa, eles acham engraçado e acho que a gente tinha que aproveitar isso. A nossa própria diversidade ambiental que eles estão tão de olho, a gente aproveita pouco" 43

Sobre os usos potenciais da diversidade natural pela moda do Brasil, Paulo Borges, fundador da Luminosidade - empresa que atualmente pertence a um grupo de investimentos - e ator principal na criação da semana de moda de São Paulo pensa algo semelhante:

Eu acho que o Brasil não pode mais perder esse bonde da sua história. Eu acho que se alguém pode vender produtos sustentáveis, ecologicamente corretos e criativos é o Brasil. Naturalmente o Brasil tem uma fonte de riqueza nessa área, de biodiversidade, de tecnologia, de natureza, que pode dar a ele uma

${ }^{43}$ Entrevista concedida à autora na sede da Luminosidade em São Paulo em $21 / 10 / 2008$. 
Os usos da diversidade cultural no mercado mundial de moda: a dinâmica das identidades nacionais na globalização

diversidade de produtos enormes nessa área. Ele começa a parecer que vai perder o bonde, mas não podemos perder esse bonde, porque vender produtos ecologicamente corretos deve ser uma etiqueta do produto brasileiro" 44 .

O próprio Kenzo, com o qual abrimos o presente texto, tem uma concepção similar sobre o assunto:

[...] sinto que o Brasil é um país super agraciado, com uma super natureza, com pessoas de todas as etnias, com muita energia e poder. [...] Acho que o Brasil vai contribuir com uma energia para o futuro, com seu ambiente feliz, rico, a Amazônia, é um país riquíssimo. Vocês têm essa natureza e, enfim, eu sinto uma super energia. Acho que vocês têm que fazer bom uso dessa energia" 45 .

Assumindo o risco de tornar a leitura exaustiva e sabendo que esses elementos merecem ser analisados de maneira mais acurada, trouxemos os discursos desses diversos atores, com distintas posições no campo, para mostrar que eles têm em comum o fato de sublinharem a posição do Brasil diante da positividade atual, no mundo da moda, das noções de diversidade cultural e de biodiversidade. Tais categorias parecem ser formas de resignificação das noções de mestiçagem e de exotismo nos tempos da modernidade- mundo. É sabido que o exotismo esteve em voga na moda em vários momentos históricos, mas, atualmente, o exótico parece mudar de condição, pois na conjuntura de globalização o Outro antes distante se torna próximo, habita ao lado e seus trajes desfilam nas Mesmas ruas. As vestimentas outrora consideradas como "costumes" ou como exóticas acedem ao estatuto de "modas" e constroem marcas, espondem como pessoas jurídicas, disponibilizam endereços eletrônicos, tornam-se acessíveis num clique, se apresentam nos salões parisienses, onde negociam em dólares ou euros... Elas fazem parte da "moda global", embora só possam despertar o interesse na medida em que permanecem "diversas" em alguma medida, ou, ainda, na medida "certa". Conforme vimos a partir de vários dos excertos acima, os agentes do setor de moda no Brasil percebem essa virada da moda mundial em direção à positividade da idéia de diversidade e fazem dela um trunfo no decurso e no discurso de criação de uma "moda brasileira" em âmbito planetário.

No entanto, nem todos os seus participantes "potenciais" se pretendem

${ }^{44}$ Palestra de Paulo Borges conferida durante a V semana de moda e cultura em São Paulo, 09/11/2008.

${ }^{45}$ Palestra conferida no Senac/SP em 21/06/2008. 
seus porta- vozes. Existem aqueles que buscam fazer uma moda "cosmopolita", mundial, globalizada, estabelecendo para tanto tentativas de libertação de amarras nacionais no momento em que a moda é entendida como "sem fronteiras", para tomarmos uma expressão de Kenzo. Nas entrevistas realizadas com responsáveis pelas empresas brasileiras nos salões em Paris entre 2009 e 2010, muitas delas foram descritas enquanto produtoras de "moda brasileira", mas outras entrevistas insistiram no caráter "cosmopolita", "mundial" dos produtos. Para citar um caso representativo externo ao universo dos salões, o único brasileiro que tem apresentado suas coleções na semana parisiense da alta costura - que, por acaso, foi modelista da marca Kenzo, entre outras, no início da carreira - nos contou em entrevista ${ }^{46}$ que fora convidado pelo presidente da Câmara sindical de alta costura para participar de seu calendário oficial em virtude de seu trabalho, claro, mas também por ser brasileiro, pois isso seria "diplomático" em uma época em que os mercados europeus voltam os olhos para o Brasil. Ele mesmo estaria tentando estabelecer "pontes" entre a Europa e algumas grandes empresas têxteis brasileiras. Contudo, quando perguntado sobre a "moda brasileira" ele afirma taxativamente que "o Brasil é muito forte em faire savoir e fraquíssimo em savoir faire", isto é, que a tal "moda brasileira" seria uma realidade mais de marketing e de discurso do que de produção efetiva.

A um mês de sua próxima apresentação na semana de alta costura que seria em janeiro de 2010 - embora ele trabalhe principalmente com prêt-àporter de luxo e tenha inclusive exposto em "avant première" na fashion week de março de 2010 -, ele nos conta o seguinte sobre sua marca:

França, eu pago os impostos na França, então é uma empresa $100 \%$ francesa. A produção é feita na França. E constituída de pessoas do mundo inteiro. Essa empresa não tem hoje capital brasileiro nem estrangeiro, só francês, por enquanto". [E prossegue] "Eu moro há 23 anos fora do Brasil, eu aprendi a minha profissão fora do Brasil, eu nunca trabalhei com moda no Brasil, eu não tenho a menor experiência de moda no Brasil. Eu não tenho porque falar de moda brasileira porque eu nunca trabalhei nesse setor no Brasil.

Em seguida, ele afirma que, para participar do calendário oficial francês é preciso ter "uma dimensão cosmopolita" e "uma cultura muito forte, mas não pode falar da sua cultura enquanto folclore". Com todo seu cosmopolitismo, a federação prezaria o fato de ele "expressar a cultura

${ }^{46}$ Entrevista concedida à autora no atelier do estilista em Paris em 23/12/2009. 
Os usos da diversidade cultural no mercado mundial de moda: a dinâmica das identidades nacionais na globalização

brasileira", de ser "profundamente brasileiro" e de estar no Brasil "há 500 anos". A receita que mistura doses de um particular brasileiro a um universal aceito parecia repetir-se, salvo por um pequeno episódio, aparentemente anedótico: na antevéspera de natal, em seu ateliê, ele nos convida a experimentar um de seus casacos que seria apresentado dali a um mês e cujas formas eram inspiradas em sua principal influência "desde sempre": o quimono!

Com esse caso, do qual poderíamos tirar diversas conseqüências, podemos perceber que a questão da identidade nacional do criador brasileiro de moda e da "brasilidade" de uma marca é algo constantemente negociado de maneira relacional. Às vezes, é importante ser "profundamente brasileiro", outras vezes é interessante ser "cosmopolita" e ter uma marca " $100 \%$ francesa" cuja inspiração principal é o quimono. O melhor é conseguir unir as duas coisas em doses estratégicas. Com isso, não estamos de modo algum denunciando qualquer forma de cinismo ou de falsidade identitária, ao contrário. Nesse aspecto, nos são novamente válidas as reflexões de Renato Ortiz:

Não devemos, porém, imaginar a identidade como algo ontológico, uma substância que 'realmente existe'. Não há 'o' japonês, assim como seria insensato falarmos na materialidade 'do' americano ou 'do' brasileiro. Uma identidade é sempre uma construção simbólica que se faz em relação a um referente. Os referentes podem certamente variar, eles são múltiplos: cultura, etnia, nação, cor, gênero. Mas sua existência não deve ser tomada como uma substância, um ser ontológico, ela serve apenas como baliza para a definição de territorialidades particulares. Neste sentido, a discussão sobre a autenticidade ou a inautenticidade das identidades é um falso problema. Desde que convincente, isto é, socialmente plausível, uma identidade é sempre válida. $O$ que não significa que seja 'verdadeira' ou 'falsa'. Dizer que a identidade é uma construção simbólica nos permite ainda indagar sobre os seus artífices, como elas são construídas, a que interesses se vinculam."(2000, p.64/65)

Para pensar a dinâmica das identidades nacionais na moda, nos é válida ainda a análise do autor sobre o "japonismo". Segundo Ortiz (op cit, p.151), no caso dos estilistas japoneses sediados em Paris a partir da década de 1970, a presença superlativa de uma "japonidade unívoca"seria contraproducente, pois os produtos devemvestir universalmente" qualquer corpo, isto é, devem ser consumidos no mercado mundial de bens de luxo, no qual o mais importante seriam os "estilos de vida" e não os pertencimentos 
geoculturais. Assim, para eles seria mais interessante reivindicar a "mundialidade" do que uma suposta "japonidade" de suas criações, pois libertando-se das "imposições geoculturais", eles poderiam ser aceitos mundialmente.

Os brasileiros, por sua vez, ora sublinham sua "brasilidade", ora a escamoteiam. Mas o que é percebido com mais freqüência é um esforço constante em busca de um equilíbrio complexo entre "brasilidade" e "universalidade". A aceitação pelo mercado mundial exige que os produtos sejam "universais", isto é, desejáveis por consumidores do mundo todo, inclusive do próprio Brasil. Ao mesmo tempo, é o caráter "diverso" dos produtos brasileiros que pode distingui-los da gama de produtos em competição no mercado. É sua diversidade, na dosagem certa, que pode diferenciá-los tanto dos "menos universais" quanto dos "mais universais". Em um equilíbrio dinâmico e tenso entre identidade e diversidade, o "caráter brasileiro" dos produtos deve ser incessantemente dosado e negociado segundo as dinâmicas dos mercados em jogo.

Essa negociação das identidades e/ou diversidades se dá de acordo com a posição relacional dos atores no espaço global. Alguns são livres para "dosar" seus pertencimentos culturais, nacionais, étnicos, etc. Outros tem de lidar com identidades fixas ou fixadas. Uma grande marca brasileira pode decidir entre ser brasileira ou cosmopolita, entre ser tradicional ou moderna, ou, melhor ainda, ela pode ser ambas as coisas, nas devidas proporções. Não é o caso da pequena empresa ou cooperativa local que não tem outra opção a não ser oferecer ao mercado a "mesma renda que a avó fazia". No mesmo sentido, Kenzo pode responder no Brasil pela moda japonesa e pela moda francesa, ao passo que tantos outros estilistas asiáticos são, no mercado global do qual fazem parte, reféns de seus pertencimentos geoculturais ${ }^{47}$.

Quando a diversidade se torna um valor no mercado mundial de moda, o sucesso nesse setor passa pelo recurso à alguma territorialização, já que a "origem" poderia funcionar como uma fonte de diversidade. Mas ele passa igualmente pela recusa da territorialização excessiva", que excluiria o caráter "universal" dos bens a serem disponibilizados no mercado global. Os bens materiais e simbólicos oferecidos como característicos de uma "moda brasileira" são contemporâneos da modernidade-mundo. Sua "brasilidade" não é constituída em bases nacionais, embora o elemento nacional seja parte fundamental de seu apelo simbólico. Como nos lembra uma vez mais Ortiz, "a idéia de autonomia das diversidades culturais deve ser revista, pois as nações e as culturas já não podem mais coexistir como se fossem espaços bem delimitados. Elas são atravessadas pelo fluxo da modernidade-mundo, sendo redefinidas segundo

${ }^{47}$ Essa discussão é sobremaneira interessante, mas sua complexidade escapa aos limities do presente texto. Para mais elementos consultar Sandra Niessen ; Ann Marie Leshkowich e Carla Jones (eds). Re-orienting fashion: the globalization of Asian dress. 
Os usos da diversidade cultural no mercado mundial de moda: a dinâmica das identidades nacionais na globalização

outros parâmetros. "(op cit, p.68).

Entretanto, isso não faz com que as nações e culturas sejam igualmente valorizadas na situação de globalização. $\mathrm{O}$ fato de o Brasil ter mais poder econômico na conjuntura atual faz dele um destino atrativo para o mercado de moda. Já as representações atuais do país como fonte de diversidade cultural e natural fazem dele uma origem valorizada para os produtos de moda. O chamado "efeito do país de origem" não é abolido na mundialização, nem suas hierarquias deixam de existir. Modas consagradas mantêm sua legitimidade, modas de países como o Brasil negociam seu espaço no mercado mundial, ao passo que algumas regiões sequer postulam inserir-se como criadoras de moda. Elas podem fazer parte do processo produtivo como confeccionistas, por exemplo, mas seguem sem voto na democracia da moda.

As modas outrora denominadas "periféricas" ou "exóticas" que conseguem inserir- se mudam de estatuto, porém, como sua condição de inserção passa justamente pela sua diversidade, elas não adquirem o privilégio do universal tout court. O universal na moda foi construído em um longo processo histórico que universalizou um particular enraizado inicialmente na França. Já as modas cujos "particularismos" não foram universalizados devem administrar e negociar, no mercado globalizado do qual hoje fazem parte, o trunfo do particular, que atualmente ganha valor positivo sob o nome de diverso. Seu esforço de universalização passa justamente pelo reforço de seu particularismo, mas um reforço ajustado às demandas do mercado mundial. Como parte dele, pode-se dizer que essas modas se globalizam, mas o fazem enquanto particulares ou, ainda, enquanto diversas.

O elogio universal da diversidade lhes permite passar de "costumes" a modas, mas não chega a lhes atribuir o estatuto de universais.

\section{Referências:}

BIANCO, G.; BORGES, P. O Brasil na Moda . Vol 1 e 2. São Paulo: Editora Caras, 2002.

BONADIO, M. C. O fio sintético é um show!: moda, política e publicidade. (Rhodia S.A.1960-1970). Campinas, SP: [s.n.], 2005. Tese de doutorado.

BONADIO, M. C.; GUIMARAES, M. E. A. "Alceu Penna e a construção de um estilo Brasileiro: modas e figurinos". Horizontes antropológicos. Porto Alegre, v. 16, n. 33, Jun 2010.

BOURDIEU, P. A dominação masculina. Rio de Janeiro: Bertrand Brasil, 1999. 

. O poder simbólico. Lisboa: Difel, 1989.

- A produção da crença. Contribuição para uma economia dos bens simbólicos. São Paulo: Zouk, 2002.

CASTAREDE, J. O luxo: o segredo dos produtos mais desejados do mundo. São Paulo: Barcarolla, 2005.

CHATAIGNIER, G. História da moda no Brasil. São Paulo: Estação das Letras e Cores, 2010.

DALBY, L. C. Kimono: Fashioning Culture. Seattle and London: University of Washington Press, 2001.

DÓRIA, C. Bordado da fama: uma biografia de Dener. São Paulo: Ed. SENAC São Paulo, 1998.

GARCIA, T. C. O "it" verde e amarelo de Carmen Miranda. São Paulo: Annablume, 2005.

GODART, F. Sociologie de la mode. Paris : La Découverte, 2010.

HOBSBAWM, E. ; RANGER, T. A invenção das tradições. Rio de Janeiro: Paz e Terra,1997.

KELLER, P. F. “Economia global e novas formas de organização da produção na cadeia têxtil-confecções". Revista Universidade Rural, v.24, n.1-2, 2002.

LAVER, J. Costume and Fashion. A Concise History. Fourth edition Concluding chapter by Amy de la Haye and Andrew Tucker. London: Thames and Hudson, 2002.

LEITÃO, D. K. Brasil à moda da casa: imagens da nação na moda brasileira contemporânea. Porto Alegre, RS: [s.n.]: 2007. Tese de doutorado.

LEITÃO, D. K. “Nós, os outros: construção do exótico e consume de moda brasileira na França". Horizontes Antropológicos, Porto Alegre, ano 13, n.28, p.203230, jul/dez 2007.

LIPOVETSKY, G. L'empire de l'éphémère. La mode et son destin dans les sociétés modernes. Paris : Gallimard, 1987.

MARQUES, D. Zuzu Angel: a identidade cultural brasileira através da moda

NEIRA, L. G. A invenção da moda brasileira. Caligrama, v. 4, n. 1, jan./ago. 2008. 
Os usos da diversidade cultural no mercado mundial de moda: a dinâmica das identidades nacionais na globalização

NIESSEN, S.; LESHKOWICH, A. M.; JONES, C. (eds). Re-orienting fashion: the globalization of Asian dress. Oxford; New York: Berg, 2003.

ORTIZ, R. A moderna tradição brasileira. Cultura Brasileira e indústria cultural. São Paulo: Brasiliense, 1988.

. "Anotações sobre o universal e a diversidade", Revista Brasileira de Educação, janeiro-abril, ano/vol. 12, número 034. pp. 7-16.

ORTIZ, R. Mundialização e cultura. 2ª ed. São Paulo: Brasiliense, 1996.

ORTIZ, R. O próximo e o distante. Japão e modernidade-mundo. São Paulo: Brasiliense, 2000.

RUPPERT, J.; DELPIERRE, M. ; DAVRAY-PIÉKOLEK, R. ; GORGUET- BALESTEROS, P. Le costume français. Paris : Flammarion, 1996.

SASSEN, S. Territory, authority, rights: from medieval to global assemblages. Princeton and Oxford: Princeton University Press, 2006.

SILVA, P. A. A moda de Zuzu Angel e o campo do design. Dissertação de mestrado. Rio de Janeiro: 2006.

STEELE, V. Paris fashion: a cultural history. New York: Oxford Univesity Press, 1999.

THIESSE, A. M. La création des identiés nationales. Europe XVIIIe - XXe siècle. Paris : Éditions du Seuil, 1999.

THOMAS, D. Deluxe: como o luxo perdeu o brilho. Os bastidores da atual indústria da moda. Rio de Janeiro: Elsevier, 2008

VILAÇA, N. "Brasil: da identidade à marca". In: revista FAMECOS, Porto Alegre, no 33, agosto de 2007, quadrimestral, pp 61-65.

WILLIAMS, R.H. Dream Worlds: mass consumption in late nineteenth-century France. Los Angeles: University of California Press, 1991.

ŽIŽEK, S. Como Marx inventou o sintoma? In: ŽIŽEK, S. (org). Um Mapa da Ideologia.Rio de Janeiro: Contraponto, 1996 